\title{
Meeting Report: Research topics in gastrointestinal disease VII
}

\author{
Organizing Committee: \\ Gordon R Greenberg MD, University of Toronto, Toronto, Ontario \\ Ken Croitoru MD FRCP, McMaster University, Hamilton, Ontario \\ Kris Chadee PhD, Chair, CAG Research Committee; University of Calgary, Calgary, Alberta \\ Paul Sinclair MSc, Executive Director, CAG
}

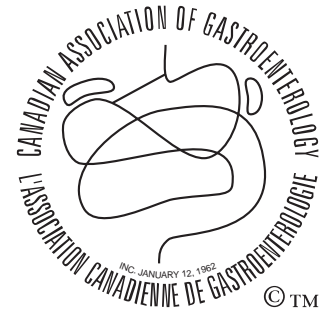

En français voir page 849
$\mathrm{R}$ ecent advances in gastrointestinal (GI) diseases are a direct result of the rapid development in fundamental research using cellular and molecular biology approaches. These approaches have helped define normal physiological processes of the GI tract and the pathogenesis of disease mechanisms. The Canadian GI research communities are world leaders in contributing to these efforts in all disciplines relevant to GI disease. This success has been achieved by fostering an excellent cohort of graduate and postgraduate research trainees involved in GI research at institutions across Canada. Many of these trainees are funded by the Canadian Association of Gastroenterology (CAG) in collaboration with the Canadian Institutes of Health Research (CIHR), a number of industry partners and the Crohn's and Colitis Foundation of Canada.

In recognition of the value of the Canadian GI trainees outstanding research contributions, and to promote and encourage the continued efforts of the graduate and postgraduate research trainees in basic and clinical sciences, the CAG, in conjunction with AstraZeneca Canada Inc and the CIHR, held the seventh Symposium on Research Topics in Gastrointestinal Disease on October 12 to 14, 2007 (Figure 1). The goal of this meeting was to provide research trainees with an opportunity to informally present their original research from diverse disciplines, to their peers and to a selection of faculty from across Canada. In this forum, trainees actively participated in the discussions of papers in an open setting. This year's program consisted of a series of superb presentations describing cutting-edge research with 44 podium scientific presentations of basic and clinical GI-related research, covering mechanisms of gut and liver infections, enteric nerves, enteric flora and epithelial barrier functions, hormones that modulate gut responses, epithelial and transport mechanisms, pathogens that initiate inflammatory processes and cancer, and gastric ulceration and healing mechanisms. This year's keynote lecture was given by Dr Stephen Vanner on "Lessons learned in the search for translation findings to treat irritable bowel syndrome."

As in previous years, a major success of the meeting was that it provided a venue in which trainees could meet their peers from across Canada and initiate collaborations, thus developing contacts for their future research career and the future of Canadian GI research. Participants rated the meeting as outstanding to excellent and described the experience as rewarding and a superb learning forum. Thus, as a result of this enormously successful symposium, the organizing committee, the CAG, and AstraZeneca Canada Inc are committed to holding this meeting on a regular basis. Plans are already underway for a fall 2008 meeting, in which, once again, research abstract submissions relating to all facets of GI health and disease will be welcomed. Canadian investigators with basic and clinical GI research programs are strongly requested to lend support to this important endeavor by encouraging the participation of their trainees and graduate students.

ACKNOWLEDGEMENTS: The organizers would particularly like to thank AstraZeneca Canada Inc and the CIHR for their generous support of this meeting, the seventh of its kind in a series that will continue to advance gastroenterology in Canada. In addition, we wish to thank the invited faculty, Drs Ron Bridges, Nicola Jones, Karen Madsen, Dana Philpott and Stephen Vanner for their commitment and valuable contributions to this meeting.

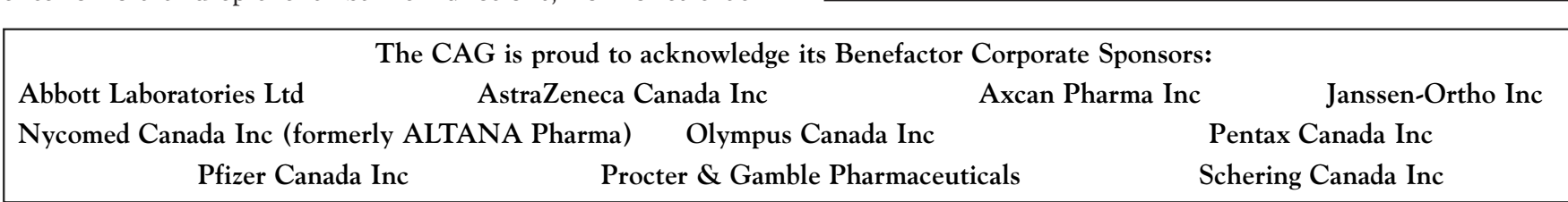




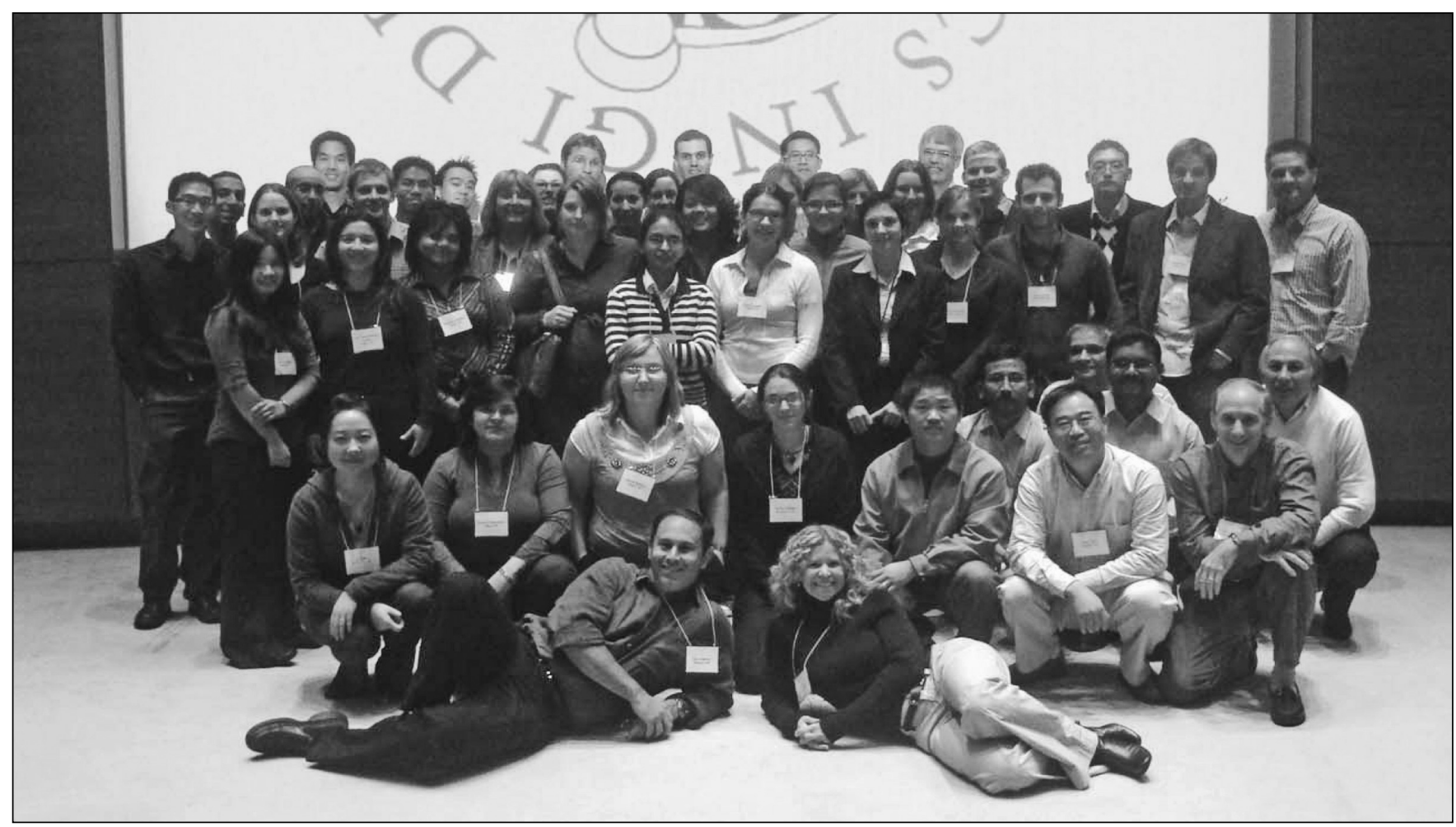

Figure 1) Participants and faculty in the seventh Symposium on Research Topics in Gastrointestinal Disease, October 12 to 14,2007 / Les participants et les professeurs au septième symposium sur les sujets de recherche en maladies gastro-intestinales, du 12 au 14 octobre 2007. Participants : Christina Alexander, Calgary, Alberta; Bianca Arendt, Toronto, Ontario; Marie Claire Arrieta, Edmonton, Alberta; Jody Backer, Edmonton, Alberta; Yannick Benoit, Sherbrooke, Quebec; Kirk Bergstrom, Vancouver, British Columbia; Dana Bronte-Tinkew, Toronto, Ontario; Scott Carmichael, Kingston, Ontario; Justin Chan, Vancouver, British Columbia; Limin Chen, Toronto, Ontario; Nina Cluny, Calgary, Alberta; Chuanbin Dai, Vancouver, British Columbia; Maaike Devries, Kingston, Ontario; Poonam Dharmani, Calgary, Alberta; Charlotte D’Mello, Calgary, Alberta; Shukkur M Faroog, Halifax, Nova Scotia; Djordje Grbic, Sherbrooke, Quebec; Armando Heriazon, Hamilton, Ontario; Ian Hons, Calgary, Alberta; Patrick Hui, Kingston, Ontario; Eric Hyun, Calgary, Alberta; Roman Iakoubov, Toronto, Ontario; Christine Langlois, Sherbrooke, Quebec; Tamia Lapointe, Calgary, Alberta; Manigandan Lejeune Virapin, Calgary, Alberta; Karine L'Ériger, Sherbrooke, Quebec; Jeffrey Leung, Kingston, Ontario; Gareth Lim, Toronto, Ontario; Gary Martin, Calgary, Alberta; Mohamed Motagally, Kingston, Ontario; Jane Natividad, Hamilton, Ontario; Pamela O'Connor, Calgary, Alberta; Brent Parkins, Calgary, Alberta; Deepa Raju, Toronto, Ontario; David Rodrigues, Kingston, Ontario; Katherine Rowland, Toronto, Ontario; Joanna Rybicka, Calgary, Alberta; Tania Santodomingo-Garzon, Calgary, Alberta; Cynthia Seow, Toronto, Ontario; Mary Sherlock, Toronto, Ontario; Isaac Soo, Edmonton, Alberta; Roger Stanzel, Kingston, Ontario; Rosemarie Stillie, Halifax, Nova Scotia; Li Zhao, Edmonton, Alberta. Faculty / Professeurs : Dr Ron Bridges, Calgary, Alberta; Dr Kris Chadee, Calgary, Alberta; Dr Ken Croitoru, Hamilton, Ontario; Dr Gordon Greenberg, Toronto, Ontario; Dr Nicola Jones, Toronto, Ontario; Dr Karen Madsen, Edmonton, Alberta; Dr Dana Philpott, Toronto, Ontario; Dr Stephen Vanner, Kingston, Ontario 


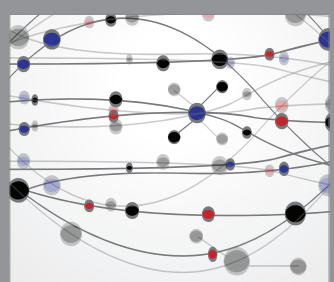

The Scientific World Journal
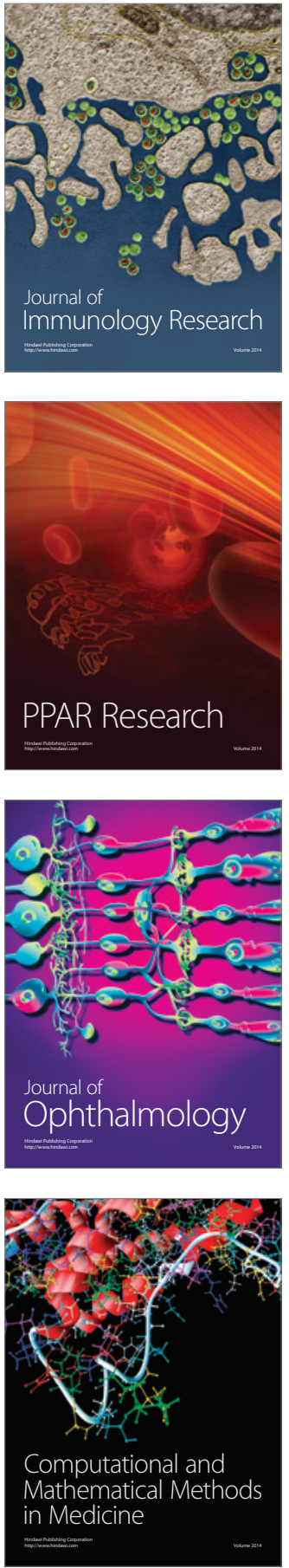

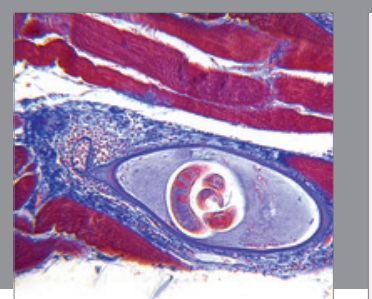

Gastroenterology Research and Practice

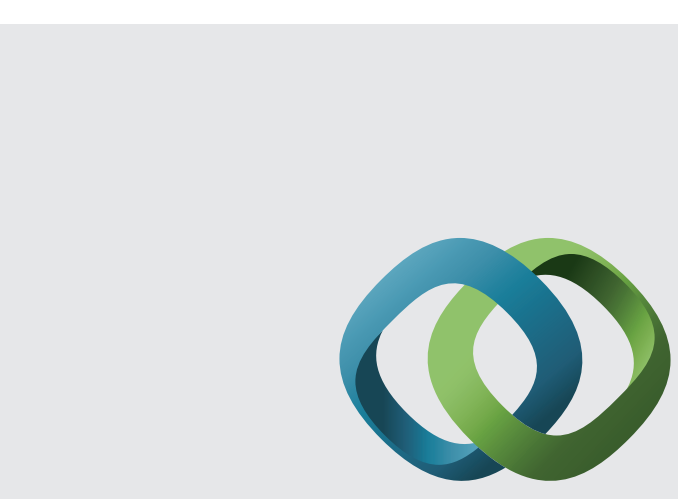

\section{Hindawi}

Submit your manuscripts at

http://www.hindawi.com
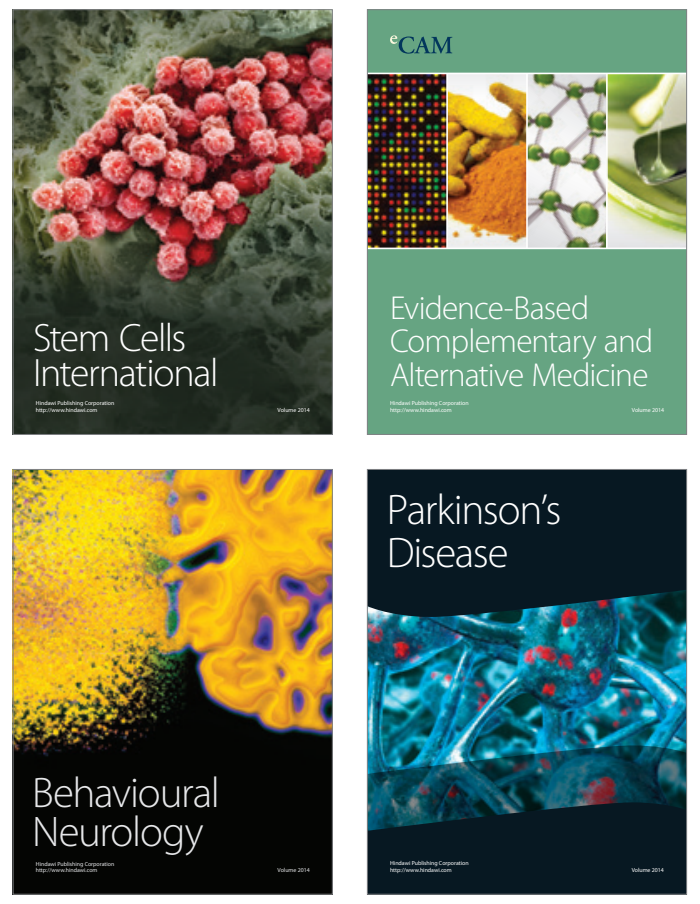
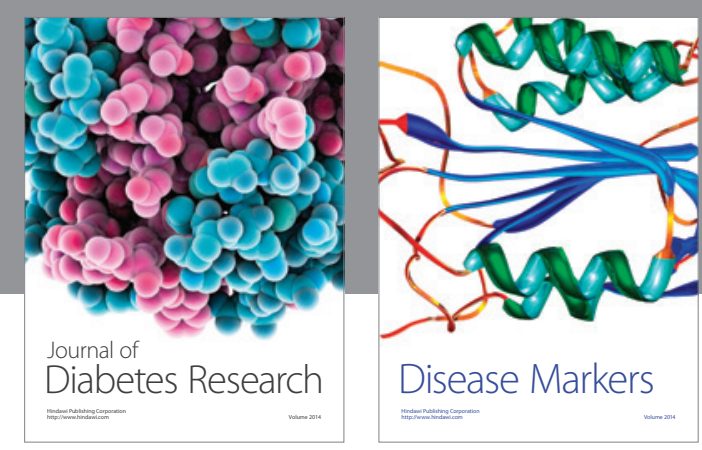

Disease Markers
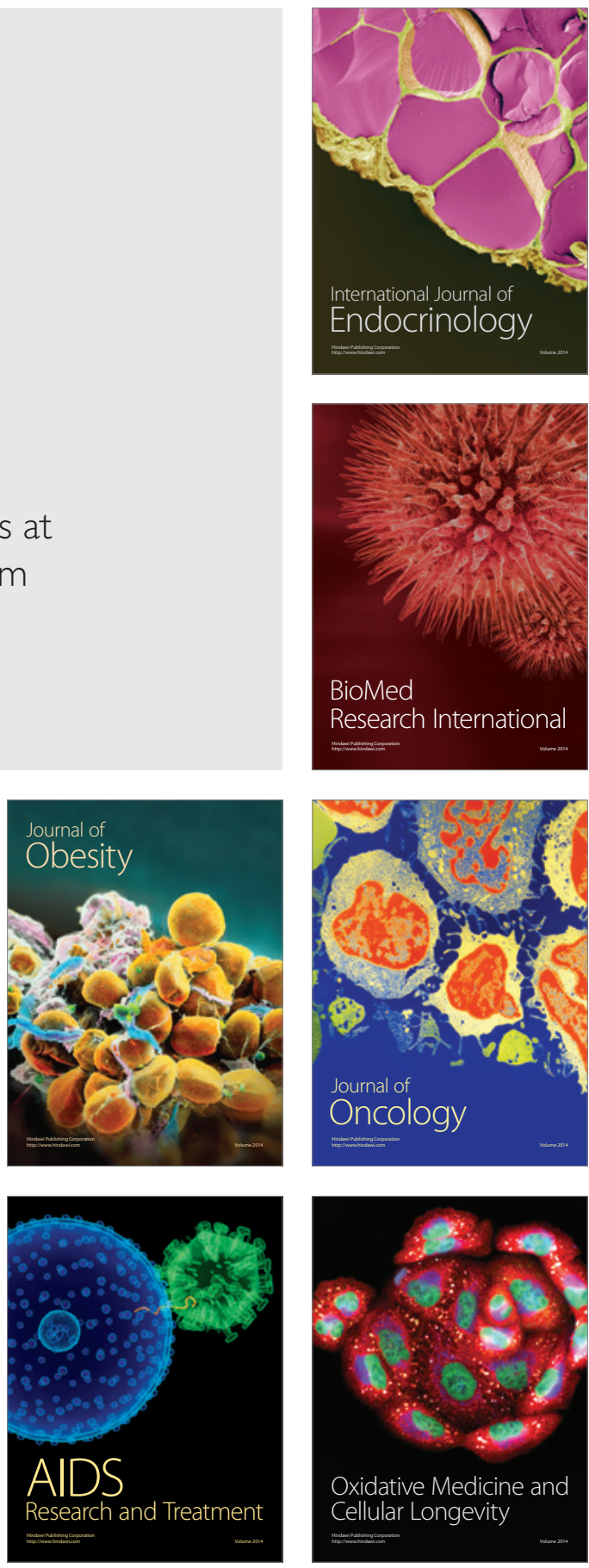